\title{
Survey Data in Teaching Project (SDiT): Enhancing Critical Thinking and Data Literacy
}

by Louise Corti ${ }^{1}$

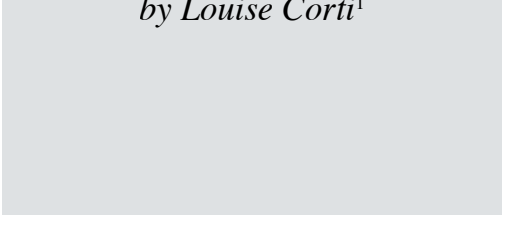

\section{Introduction}

Through a number of strategic investments by various funding organisations, the UK academic community has access to a unique and expansive range of digital data resources. The Economic and Social Data Service (ESDS), supported by the Economic and Social Research Council (ESRC) and the Joint Information Systems Committee (JISC) is a national data service. ESDS provides access and support for an extensive range of key economic and social data, both quantitative and qualitative, spanning many disciplines and themes. ${ }^{2}$ It comprises a number of specialist data services that promote and encourage data usage in teaching and research. While individual datasets are used extensively in academic research, they are significantly under-used in learning and teaching programmes within Higher Education (HE), at both undergraduate and postgraduate levels, and are rarely used in Further Education (FE).

As a service provider of the ESDS, the UK Data Archive (UKDA) is in a strong position to offer its data resources to the learning and teaching communities for developing materials that might be more appealing to teachers than raw data. ${ }^{3}$ This activity requires advice and input from instructors in the classroom on how to develop the pedagogic aspects of learning resources: which content to extract; how to contextualise and apply raw data; where to position such resources in the learning process; and on the usability and functionality of the digital resources created.

This paper describes the UKDA Survey Data in Teaching project (SDiT), funded under the JISC Exchange for Learning (X4L) Programme. ${ }^{4}$ The project's goals were to increase the use of real data sources in the classroom, and in a more ambitious sense, to help improve the data literacy of those studying social sciences, from school students age 16-19 to postgraduates. The project created a set of free teaching and learning data and statistics-oriented resources based on the study of crime in society, and were based on learning strategies that encourage the teaching of research methods within a substantive context. This paper addresses both the positive experiences and challenges that arose from running the project. ${ }^{5}$

\section{Background: under-use of data in the classroom}

There is a widespread concern in the UK and further afield, including in the US, that levels of data literacy are at an all-time low. Previous investigating into levels of data literacy reveal that the UK is lacking significantly in a stock of individuals with good quantitative data analysis skills. The JISC 5/99 Programme Task Force on The Use of Numeric Data in the Learning and Teaching project, centred around how quantitative data are currently used in the classroom, offered valuable insights and evidence into the benefits and barriers surrounding the adoption of data handling in social science teaching practise (Rice et al. 2001) ${ }^{6}$. The enquiry looked into the use of numeric datasets in learning and teaching within UK higher education, and into the barriers faced by postgraduate and undergraduate teachers who wish to introduce students to the use of empirical datasets in the classroom. The few HE lecturers using data in their teaching used them either to add an empirical dimension to the subject, to teach statistics or data analysis methods, or to teach numeracy or critical thinking skills. Certainly, the main focus is on using data to teach research methods, with very few using 'live' social data to illustrate substance. For teachers, the barriers to using data cited in the report were largely to do with lack of awareness of data sources, lack of access to suitable data both physically and conceptually, and lack of time available to prepare data and build its use into courses.

The UKDA has years of experience working with lecturers in the HE sector, but mostly in responsive or passive mode. That is, a teacher requests a survey on health of older people for her course on gerontology, and the UKDA has previously done little to service the request other than advise on the most suitable choice of data or teaching datasets already prepared (by other teachers and then redeposited). However, user surveys suggest that even those who do access data do not go on to use them in their teaching for the reasons mentioned above.

The ESRC has also recognised the problem regarding the deficit of quantitative research methods skills of social science 
postgraduates, and has recently introduced strategies to try to redress the situation. An example is the introduction of mandatory quantitative methods training courses for PhD students (ESRC 2001) ${ }^{7}$.

Turning to mathematical education of post-14 school age children in the UK, the recent report, Making Mathematics Count, suggested that current curricula fail to meet the needs of learners and satisfy the requirements and expectations of employers and higher education institutions (Smith 2004) ${ }^{8}$. The Department for Education and Skills (DfES), with guiding support from bodies such as the Royal Statistical Society, is thus seeking to improve ways to give young people confidence with numbers and in data handling across the curriculm, not only within the confines of mathematics education per se. An example of a participatory project for school children is the CensusAtSchool project (2003)9. Last year, the Tomlinson Report (2004), which looked at UK secondary education, proposed major reforms for a new diploma-based system designed to offer more specialized work-related learning that would also better prepare students for higher education ${ }^{10}$. Key to the recommendations was the requirement of all students to complete core communication and numeracy skills elements.

Evidence from the US suggests the same worrying situation (Steen 2004), and various forums have been established, such as the National Numeracy Network (NNN) by the Mathematical Association of America (MAA), to help support schools and colleges that are exploring ways to infuse quantitative literacy into their curricula ${ }^{11}$. The Department of Education has already set up a "Fund for the Improvement of Post-Secondary Education" (FIPSE) which, in 2004, awarded Carleton College in Minnesota an award to support of a three-year project on education in quantitative reasoning ${ }^{12}$ And, other US initiatives have also become more prominent to help foster statistical literacy at the graduate level, for example, the StatLit website ${ }^{13}$.

It is now widely accepted that the benefits of working with real life data sources are significant. These include understanding how statistics are created, how published tables and graphs (e.g. opinion polls in newspapers) are interpreted and how to begin to manipulate and analyse data. Not only does practical knowledge about survey methods and secondary analysis teach students how research is actually conducted, it informs critical assessment of arguments based on the interpretation of survey data. Data are never isolated from theory, and it is never the case that data 'speak for themselves'. Introducing such concepts early on in post-16 education is one way to address the quantitative skills concerns expressed above, and students gain a tangible and marketable skill that they can use in future employment. From a pedagogical point of view, these inquiries provided the driving force behind the SDiT project.

There are still relatively few instances of good examples of repackaging the rich stock of national data resources amongst the social science teaching communities. The JISC Collection of Historical and Contemporary Census Data and Related Materials (CHCC) project is one of the first funded activities to look at creating e-learning resources for statistics in context based on census data (CHCC 2003) ${ }^{14}$. The SDiT project adds to these initial building blocks.

\section{Aims of the SdiT project}

The SDiT project was funded under the Exchange for Learning (X4L) Programme, which has been motivated by the drive to make the most of the considerable investment that has taken place in a range of JISC resources for teaching and learning. The Programme is exploring a range of strategies, methods, tools and metadata standards that will enable the repurposing of e-learning materials. Pedagogical outcomes are at the heart of the Programme, with a focus on learning activities and outcomes, as is the challenge to elucidate strategies that will encourage sustainability and widespread adoption of e-learning materials.

In attempting to meet the Programme's key challenges, the SDiT project aimed to consider how repurposing existing data resources housed at the UKDA for teaching and learning might increase their use. Simplifying and re-packaging complex data, for example, the larger national government survey datasets held by the UKDA, is one way of opening up their accessibility to the classroom ${ }^{15}$.

The initial aims of the project were: first to develop, pilot and evaluate a set of survey data-base resources for use in the teaching of social science courses at both HE and FE levels; and second, to document the experiences, process and outcomes of the project itself. However, a longer-term aim of the SDIT project was to find ways of helping teachers and learners work towards improving the data literacy of GCE (General Certificate of Education) 'A' level and university students to:

- $\quad$ enable a better understanding of the use of social science data as applied to real life problems;

- $\quad$ enhance skills in manipulating numerical data - textbooks, newspapers, reports and databases;

- conceptualise the characteristics of quantitative data so that they can be used to support substantive arguments; 
- increase the ability and confidence of students in producing and communicating data;

- become critical consumers of these data.

The key objectives of the project were to:

- produce stand-alone and integrated teaching datasets from more complex socio-economic datasets;

- develop an integrated web-based learning and teaching resource that links together resource discovery tools, and data exploration and extraction tools (Nesstar) with teaching materials that help address substantive issues for social science teaching;

- gain evaluation and feedback from piloting this repurposed content in the area of social science teaching in the HE and FE sectors;

- provide a model for improving the productivity of teachers by reducing the resources (time and burden) required to incorporate data related resources into learning and teaching courses;

- improve access to key primary data sources and related resources for the learning and teaching communities;

- promote increased and more effective use of a national data services for

problem-based learning in the classroom, at all educational levels.

And more specifically, the project's deliverables included:

- the creation of new and easily accessible dataset-based on the 2000

British Crime Survey conducted by the Home Office ${ }^{16}$;

- accompanying engaging and uncomplicated substantive learning materials and a user guide to resource discovery;

- an intuitive and flexible means of delivering these materials, via Nesstar ${ }^{17}$ and via the UKDA Download service;

- tutor's guides with scenarios of usage;

- high quality and standardised descriptions of the resources, linked to other key web resources in this area (such as SOSIG resources ${ }^{18}$, the Virtual Training Suite (VTS) Internet Tutorials ${ }^{19}$, the Office of National Statistics ${ }^{20}$ );

- an evaluation and awareness raising strategy, together with reports from evaluations with project advisors, tutors and students;

- a fully documented 'warts and all' report on the processes used to repurpose and pilot the learning materials, and ideas on how, seeing a prototype, the model could be applied, or repurposed, in a wider sense to other subject areas based on existing UKDA data resources.

Thus the focus of the content of the SDiT resources was to integrate the mechanics of data analysis with theoretical material. The developments and outputs were conceived to be intrinsically linked and aimed to ensure that students gain a better understanding and knowledge of the nature, context, extraction, manipulation, visualisation, statistical analysis and interpretation of key social science data sources. These skills must be grounded in substantive and intellectual reasoning in relation to the taught subject or curriculum. Methodology for methodology's sake is never a useful way to introduce quantitative reasoning to the social scientist. Rather, furnishing the beginner with the applied skills to be able to appreciate the potential of survey data to answer research questions is a more appealing approach.

Repurposing in the case of this project meant re-packaging complex data with educational narratives and exercises into discrete 'chunks' which could then be tried and tested by tutors and incorporated into their teaching in a flexible way. One further key outcome initially envisaged was to ensure that the resources encouraged an easier route to accessing data, metadata, learning materials, and data exploration/visualisation tools, and thereby encourage student-centred learning and the development of appropriate skills for undertaking project-based work. As such, the resources might be as applicable to distance as to class-based learning.

The small scale project ran over eighteen months with a team of four part-time staff. 
The teaching and learning resources created

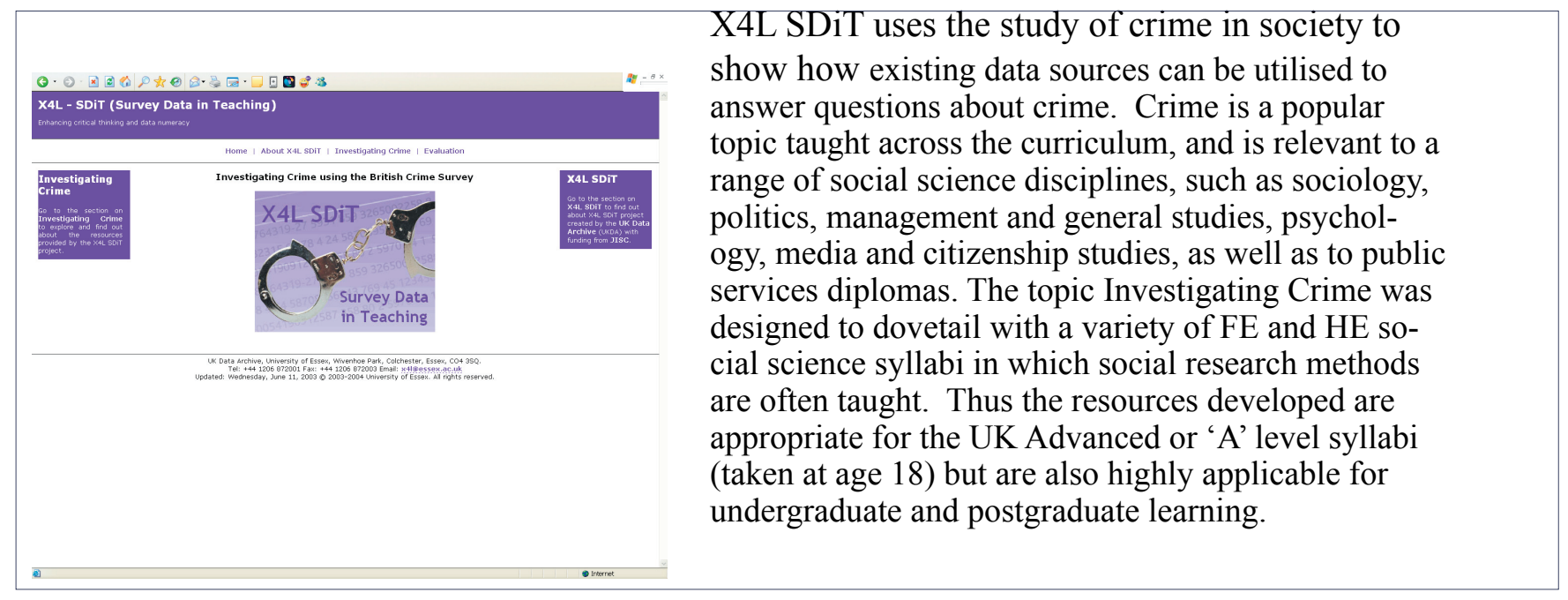

The outputs created were a variety of free teaching and learning resources relating to social science and statistics, based on learning strategies that encourage the teaching of research methods within a substantive context.

The following resources were developed: four
learning modules on the use of crime data; two
appendices on sampling and statistical inference;
a glossary of statistical terms, and two resource
discovery guides, one on the use of the Nesstar
online data exploration- system, and another on
how to find data and documentation (resource
discovery) in the UKDA. The latter two general
user guides to exploring and accessing the data
collections housed at the UKDA have wider more
general appeal and are less syllabus oriented.

The modules covered the following areas:

- Module 1: Tracking Crime: Police Recorded Crime Figures, Trends and Reasons for Change;

- Module 2: Theories about Crime: Public Perceptions of Crime Rates;

- Module 2 Appendix: Crime and Political Parties, aimed at politics students;

- Module 3: Gathering Evidence: How to Investigate Crime Statistics;

- Module 4: Examining Evidence: How to Interrogate Crime Statistics;

- Module 4 Appendix: Reliability of Results;

- Module 5: Resource Discovery - Searching for Evidence: Sources of Crime Data;

- Module 6: Guide to using Nesstar. 
Starting from simple graph reading skills, the most "complicated" data analysis task reached in these modules is actually only a three-way cross-tabulation and resulting measures of association. The concepts of reliability, sampling, and statistical confidence discussed along the way are perhaps the most complex. Appendix A sets out the data literacy and data analysis concepts covered and skills to be learned in the modules. Figure 1 sets out the skills to be learned as one moves sequentially through the six modules.

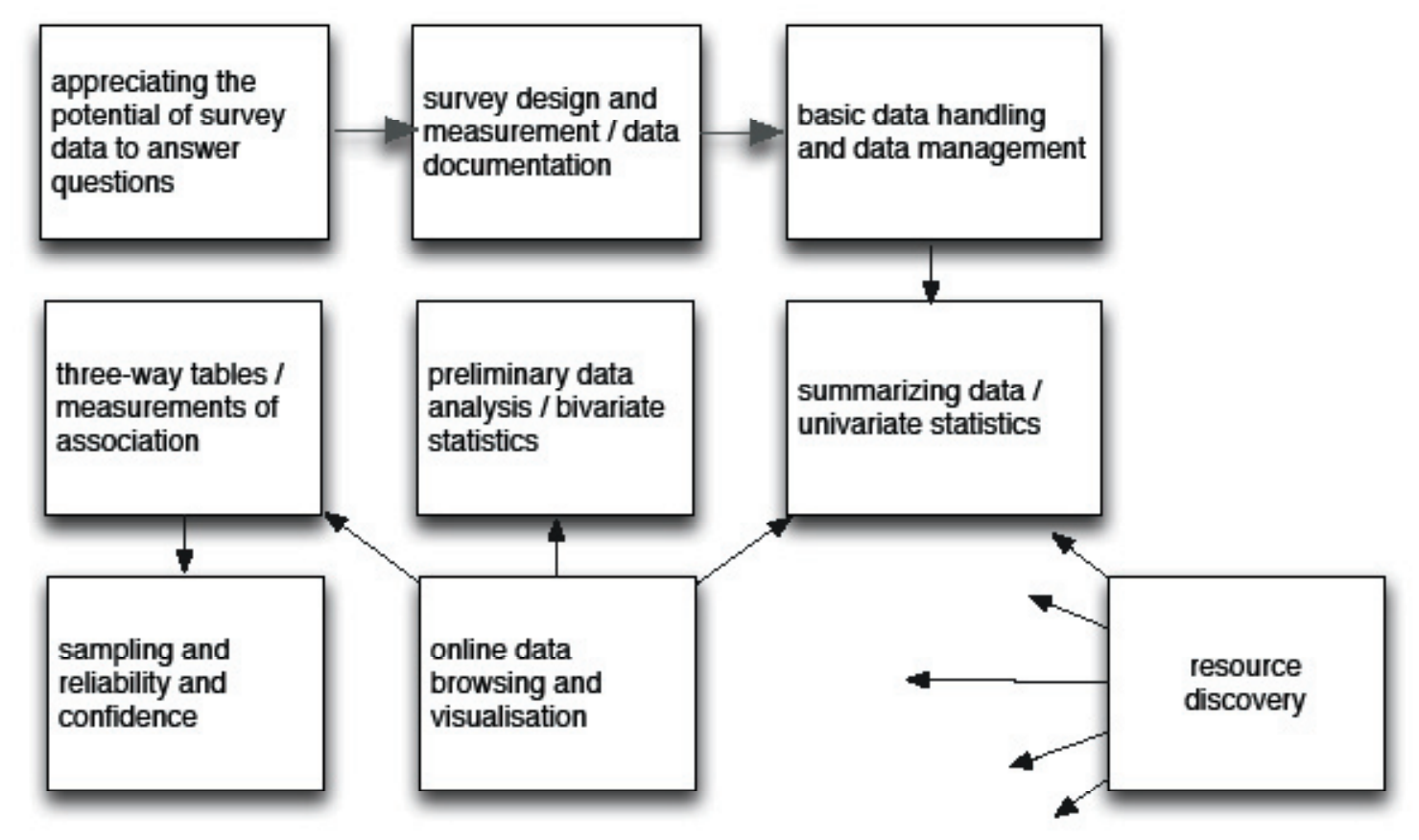

Figure 1. Flow diagram of stepwise learning skills used in SDiT project

Modules were designed to be used as part of standard classroom teaching or as additional/self-paced learning activities and were created in a number of formats to suit different pedagogical needs:

- online, interactive self-paced modules hosted (long term) at the UKDA web site

- printable and reproducible hard copies:

- $\quad$ bound paper workbook with accompanying CD-ROM

- $\quad$ Microsoft Word files

- $\quad$ Adobe PDF files

- Microsoft PowerPoint presentations which can be used to provide slides or handouts

The project also created freely available new teaching datasets and access to data exploration software, for which a guide to accessing them for the data handling exercises was also provided: 
- a restriction-free teaching version of the British

Crime Survey dataset available in multiple for-

mats (SPSS, STATA, NSDstat and tab delimited (suitable for MS Excel) and available from three systems ${ }^{21}$ :

- $\quad$ via the freely available online browsing system, NESSTAR: the data can be explored directly online using very simple point-and-click procedures or the dataset can be downloaded from the site and imported into other software, such as Excel or SPSS;

- $\quad$ via the UKDA online web download/ ordering system;

- $\quad$ via the NSDstat data analysis software available from the X4L project website or SDiT CD-ROM ${ }^{22}$

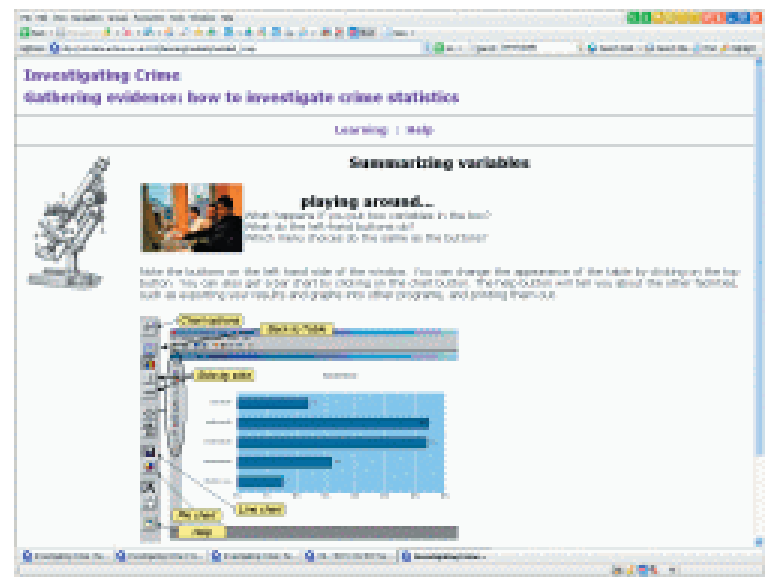

- $\quad$ via the $\mathrm{X} 4 \mathrm{~L}$ project website or SDiT CD-ROM.

For promotional purposes, the resources listed above comprising the modules, guides, data and data analysis software, were printed and bound as an SDiT Resources Pack, with an accompanying CD-ROM.

A Tutor Guide to accompany the resources was also been prepared which gives model answers and suggestions for classroom exercises, ways of using data resources in teaching, providing an exemplar/model of how such resources could be applied to other topics e.g. health, race etc, model answers to the quizzes, SPSS syntax for data analysis exercises, and a mapping of the resources to Key Skills levels 3 and 4, that is, appropriate to ' $A$ ' level' ${ }^{23}$. Finally, case studies of using the SdiT resources, based on feedback and usage of the resources in the classroom by tutors and students were included.

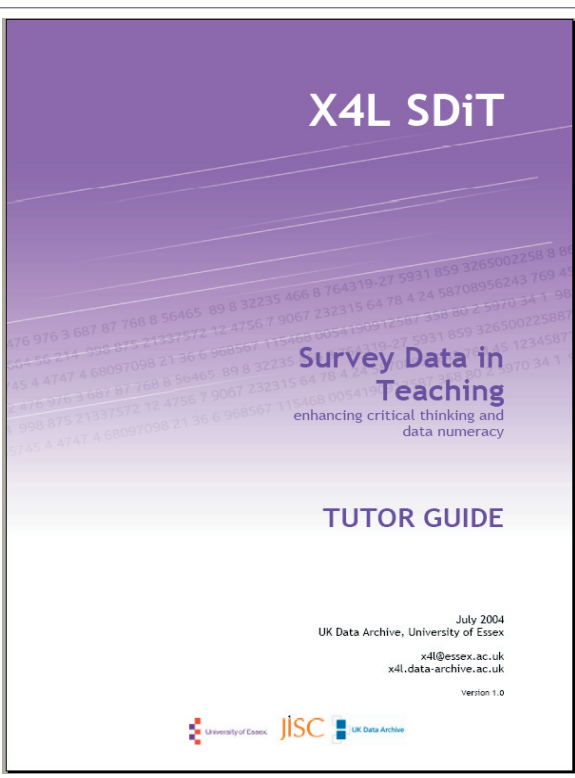

Experiences of repurposing data resources for learning data literacy

From the start, the project considered it critical that the pedagogical concerns drive the content of the resources which should then be 'translated' to the teams building and implementing the resources. The modules for HE and FE were authored and piloted primarily by lecturers who are responsible for teaching quantitative skills in social science (in political science 
and sociology). The FE teacher was formally bought out from his teaching for 25 days over the life of the project and the HE tutor, who helped construct the initial grant application, was donating his time voluntarily. The extraction of teaching datasets, writing Nesstar user guides, designing and building the web interface (and CD-ROM) for the resources, undertaking evaluation activities, and creating promotional materials, was delegated to staff at the UKDA.

A close working relationship was built between the UKDA project staff and the two tutors, with regular brainstorming sessions and progress meetings. The experience of working in partnership with tutors also helped at the evaluation stage when rich feedback could be obtained from their trialing the resources in their own teaching. Moreover, the pedagogical aspects of the resource creation and implementation could be documented (by them) in the tutor guide and in final reports.

\section{Lessons learned}

The first and most important lesson learned from the project was that drafting resources that aim to be relevant, appealing, flexible, light-weight, 'discrete' rather than courseware, and suitable for web-based delivery, takes up exponential resources: time for coordinating, authoring, evaluating, rewriting, mounting on web and promoting. The process of deciding upon a suitable topic and authoring the material to be generic enough to answer key learning concepts, yet specific enough to meet the needs of syllabi, actually proved to the most complex of the tasks. Thus, while the aim of promoting 'customizable' repurposing is valuable, the production of new content was far from straightforward, requiring considerable subject knowledge and creative skill, as well as technical ability, to supply freely downloadable software and comply with current web standards.

The second lesson learned was that while we had initially envisaged that reaching out to FE teachers across the UK would be a matter of procedure, it was not. Teachers are hidden away, embedded within the burrows of their own colleges, and rarely have time to venture out into the world outside the conventional classroom. There are some six hundred FE colleges within the UK and there are no e-mailing lists to which they systematically subscribe, even within their own disciplines. Finding ready and willing evaluators for the resources was a major challenge!

Lack of foresight in these two matters (drafting of the resources and evaluation), meant that an extension of 2.5 months to the original 16 months project duration, was requested (and granted) from the funders. We would certainly recommend that other repurposing projects allow more time to author materials and allow for iterative editing between rounds of testing. It is also impossible to rely simply on the goodwill of tutors, and involvement of tutors needs to take into consideration an extended period of buy-out of their time. That said, even then the repurposing will probably require a single core project staff member to pull together the content / testing / mounting for delivery / user guide preparation / promotion and user support. In the case of the SDiT project, mid-term, we had to buy in a new project officer, with prev.

The original evaluation plan was conceived as a small and informal programme of work, focusing on feedback from the two teachers involved in the project testing the resource themselves, and on a small group of their students. The local FE tutor with whom we worked was unable to test out the web-based resource according to the planned timetable. The 16-19 syllabus timetables are extremely rigid, and to conduct real-time class-based evaluation that coincides with appropriate points in the curriculum is no simple task. In retrospect, we would have benefited from allowing more lead time for securing evaluators and testers to cope with the inflexibility. Earlier reaching out to FE teachers and information and learning technology staff and detection of 'champions' would have been better done earlier, but the whole 16-19 learning territory area was unfamiliar to the UKDA. Nonetheless, the local FE tutor's experiences provided us with a useful comparison of three ways of teaching a single topic: with and without the new learning pathways and resources that had been constructed in this project (written up as case study in the Tutor Guide).

Finally, we did not anticipate the need for extended checking/proofing of all materials, after each editing iteration, and the time taken to undertake promotional and outreach work, which mushroomed as news of the project spread.

\section{Feedback from teachers, students and library support staff}

The major pedagogic challanges for e-learning uncovered in this project concern the building of suitable content, interest value, comprehensiveness, complexity, sequencing, relevance and fit to syllabus, key skills, and positioning in the learning process.

The HE and FE staff and students, and information professionals who helped advise on and evaluate the project, were asked to consider these issues during the phases of evaluation. On the whole, evaluators considered the learning materials and associated guides created by the project to be impressive and highly useful. Moreover, they felt that the project had delivered a neat and flexible model that both answered the data literacy challenge in hand and demonstrated the concept of repurposing. 
Pre-prepared materials can save teachers considerable time and effort, and also offer ideas of how to utilize data sources in their own teaching.

While the SDiT resources span both 16-19 and undergraduate/postgraduate levels, the levels of learning are demarcated: the more advanced FE students can investigate the latter modules, while many undergraduates (or postgraduates) may benefit from seeing these as a basic revision session. However, in the evaluation phase of this project, some FE level students did undertake all six modules without a problem, and likewise, some postgraduates who took on the whole six modules found the experience highly complementary to their existing knowledge base. Case studies from the teacher and student evaluations have been written up and are published in the SDiT Tutor Guide ${ }^{25}$. These were found to be highly instructive, providing exemplars of how to the resources can be used on the shop floor and may entice the more curious or more cautious teachers to think positively about incorporating such approaches.

A final round of intensive publicity has resulted in recent feedback suggesting that the resources are indeed offering teachers greater awareness of the potential and relative ease of utilising raw data held by UKDA, and that they wanted the printed and CD-ROM SDiT resources off-the-shelf (not necessarily the web versions!) . We hope they might be inspired to use the repurposing methodology to create their own similar materials in the area of data literacy instruction, although it is questionable as to whether they would have adequate support to 'indulge' in the areas of technical competence and web standards-compliance, as we did for the SDiT web resources. A new project recently started at Essex is taking the SDiT model and rewriting the substantive content to cover investigating health issues. While this is being done by lecturers and an ex-data archivist under a small-scale dedicated teaching and learning grant, there is continued liaison with the SDiT team at the UKDA.

Thus, adaptation of e-learning resource by teachers is seen to be most fruitfully supported by the holders of basic resources, for example, data service providers such as ESDS. High quality learning materials may be most usefully developed by teachers working alongside ESDS and e-learning implementers to build subject-specific, or concept-specific sustainable dataoriented resources. We believe that those that can map the resources to a common syllabus will be requested most.

The mapping of modules and resources to syllabi and Key Skills (levels 3 and 4) in the SDiT resources was attractive to FE tutors. In this way it would be easier to quickly identify appropriate materials from learning banks or repositories for use in their own teaching.

Finally, technical issues to do with hosting and sharing web resources also arose as important matters for HE and FE institutions. The incompatibility of different Virtual Leaning Environments (VLEs), such as BlackBoard can cause huge problems for importing web resources that have been described and sequenced using a Content Package. ${ }^{26}$ This suggests that resources should be kept simple, probably avoiding the use of complicated style sheets.

\section{Sustainability of e-learning resources}

One of the features of the X4L Programme under which this SDiT project was supported was the building of models to support longer-term e-learning resources. Metadata about the SDiT web and non-web based resources (using the UK Common Metadata Framework for learning objects) was submitted to the test-bed learning and teaching repository, now set up as a service known as the JORUM Online Repository for Learning and Teaching Materials ${ }^{27}$.

Although an explicit exit strategy was not part of the project plan, nor a requirement of the X4L programme, it was always considered by the SDiT team that it would be desirable to have an appropriate continuation strategy that ensured the ongoing maintenance (hosting and functionality) and promotion of the resources, and findings pertinent to the remit of the UKDA's longer term strategic objectives. It is harder to consider the resources that might be required to continually update the content of data to reflect currency of data and trends, but it is clear that in ten years time statistical results based on 2000 crime data will appear rather out-of-date and, quite probably, unappealing to the student.

Indeed, the issue of keeping content current is a challenge that many e-learning resources, and learning repositories, need to consider. The SDiT project produced exemplar, rather than one-off static resources and a methodology/template for repurposing social science data to help teach key concepts in introductory data literacy and statistics. Our own view is that it is probably best for teachers to engage in the revision/updating process so that the learning materials meet the specific needs of their own topics taught. Where possible, data services like ESDS can help contribute by providing the appropriate data, but could certainly not engage in the extent of involvement that was required to create these SDiT resources.

Equally, web-based resources must keep pace with the ever-changing web standards. And, on metadata matters, the work 
involved in having to remap resources to new evolving metadata scheme or new thesauri, could also pose serious barriers to maintenance.

It is evident, from this small scale project, a toe-dipping exercise, that embedding strategies are required to get e-learning resources for social science used on a widespread, taken-for-granted basis. There is a need to reach out to teachers on the ground, via discipline-specific workshops and road-show events, in addition to Information and Learning Technology staff, within educational institutions. New different teaching and learning styles are often slow to filter into mainstream educational practice and can often be better implemented from a top-down directive rather than a more passive bottom up approach via a handful of pioneering tutors.

This work requires promotion and encouragement from organisations and policy makers in fields of education and ILT, and also national examining boards, to help utilise JISC resources and Programme outputs like the X4L, and to help join up the many disparate e-learning initiatives.

\section{Joined-up initiatives?}

Sadly, many of the recent e-learning initiatives, at least in the UK, that have arisen over the past five years appear far from being joined-up and very few have given rise to sustainable subject-oriented products. Different funding organisations have been competing to pioneer e-learning across the learning spectrum. This parallel universe results in replication and noncollaboration, and often the untimely death of the expensive e-resources that have been created, simply because sustainability has not been built in to the programme plan.

Even in 2004, it was evident from undertaking this project that competitive streams still exist. We found out about two large-scale projects working broadly in the area of statistical literacy who knew nothing about the JISC activities until we contacted them. And, the attempts of our project tried to engender mutual recognition between two such programmes was met with disinterest. A second example is with repositories of learning materials that are cropping up. Many are replicating or ignoring work already done by data archives, for example, in the case of establishing vocabularies for social science data resources, designing teaching materials that support particular social science data, and attempting to cover user support for the materials. Quality assurance procedures for the submission of specific materials (sometimes covering analytical or technical matters) into these repositories is also worryingly absent: in other words the potential for garbage in-garbage out.

Mutual experiences can be shared by joint events and thematic publications. Fortunately, the Association for Learning Technology (ALT) does have a lively cross-disciplinary community that has well-attended lively events and a regular news outlets $^{28}$.

\section{Future support for data literacy e-resources}

It is critical that funding bodies, like the JISC, help create further opportunities through networking and funding to create further novel and engaging teaching materials in the area of data literacy that is currently still lacking in a choice of eresources. Such future e-learning programmes should be oriented towards methodologies and strategies for embedding learning objects into teaching and learning practise.

This SDiT project's start coincided with the initiation of the ESDS, for which proactive and dedicated support for users of four particular types of data was strategically built in to its remit. The data types are: complex household surveys; longitudinal panel and cohort studies; multi-country macro databanks; and qualitative data. This is over and above the core ESDS services of data archiving, dissemination, and preliminary user support. Through its four help desks, ESDS is able to offer reactive tailored and sometimes, analytic support to users, and run a full programme of outreach events that deal with: resource discovery; data confrontation; getting started with data analysis software packages; conceptually more difficult issues like weighting and linking data; and best practice in data creation and management ${ }^{29}$. All of these areas touch on data literacy.

At the time of writing this paper, a second application to the JISC was submitted under Phase Two of the Exchange for Learning Programme, looking at creating sustainable data literacy video tutorials with two other institutions. The follow-on programme provides an opportunity to build on what $\mathrm{X} 4 \mathrm{~L}$ has done on repurposing and extend this to re-use and to explore issues associated with buy-in and embedding at an individual and institutional level.

While the grant was turned down, the SDiT project staff continues to seek to foster new collaboration with educational communities and pursue funding opportunities for e-learning initiatives based on UKDA resources, where this is considered to be beneficial to the remit of the UKDA. Equally, it might be worth pursuing a business plan in order to further continued 
productive collaboration of UKDA with teachers. Repurposing requires devoted and skilled staff with complimentary talents to author the materials, pilot and convert resources to web-based media. Writing honed to appropriate pedagogic levels, and adequate technical skills are instrumental to the success of the content and learning objects created. This model would thus need to support dedicated core staff to make links with teachers expressing an interest in partnership. At a minimum, personnel devoted staffing would require:

- one senior officer trained in social science methodology and data analysis to provide:

o reactive and proactive to support to users;

o help prepare data;

o collaboratively draft associated resources;

o run promotional road shows;

- and one part-time web and metadata officer to:

o create web-based standards-compliant materials hosted at persistent websites like UKDA;

o prepare metadata for resources to go into the national learning repositories.

A budget should also not skimp on costs to cover promotional outputs and activities. Indeed, data service providers would be better suited to having this type of staff available in 'permanent' positions in-house, as relying on short-fire funding means that expertise is quickly lost as fixed-term contract project staff move on (the skilled senior UKDA staff working on the SDiT project have left due to contracts expiring).

\section{Conclusion}

From the UKDA's point of view, this project has enabled us to promote UKDA's existing portfolio of data and online data access tools, such as Nesstar, to the teaching and learning communities, which will, hopefully foster new interests in utilizing survey data. If there is one key area from which the UKDA benefited, it was the chance to engage with the world of Further Education, to help appeciate better its infrastructure, IT and pedagogical concerns surrounding core social science teaching and data literacy. Exploring ideas and gaining feedback about repurposing data collections for the FE community should have a pay-off for Economic and Social Data Service and for its funders if data resources that are 'enhanced' for educational use become popular, or even mainstream within this sector. Any further uptake of social science data and associated tools, by the teaching and learning communities would be a significant achievement.

\section{Appendix A: Overview of learning modules}




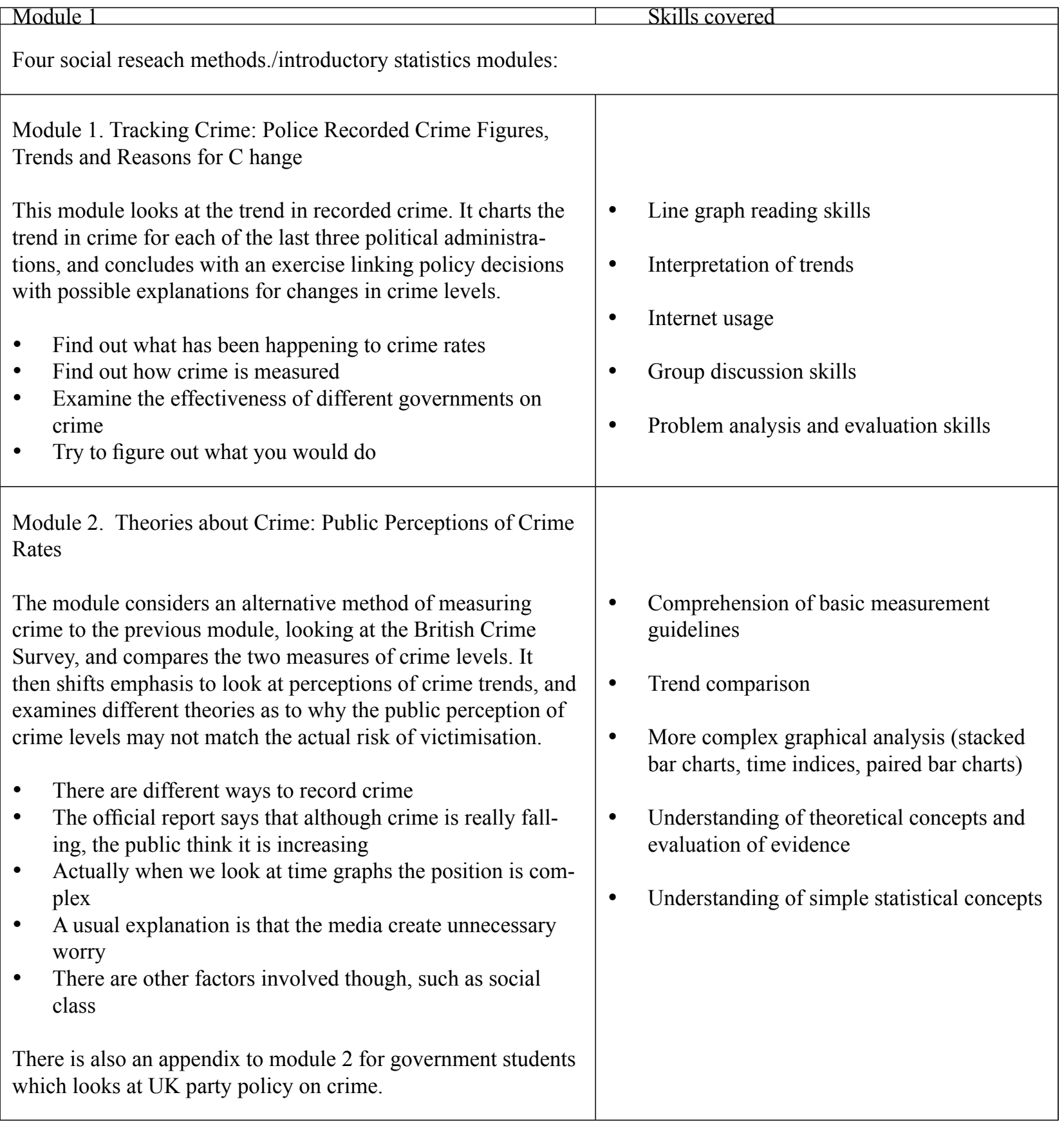


Module 3. Gathering Evidence: How to investigate crime statistics

This module is concerned with the concepts of operationalisation and validity, and with basic descriptive statistics. It shows how to use the NESSTAR site to find out information about the British Crime Survey, to constructively criticise the validity of data used in reports, and to use the simple computer program to generate descriptive statistics, frequency tables and graphs.

- Learn about devising measures for concepts

- Learn how to describe large sets of numbers using one or two numbers

- Learn how to make and interpret straightforward tables and graphs

- Learn how to cite sources properly

- Learn how to use an undemanding data analysis program

Module 4. Examining Evidence: How to interrogate crime statistics

This is a skills-based module concerned with explaining the analysis of associations between two variables.

- Learn how to alter data

- Learn how to examine associations between two variables

- Learn how to present and analyse data in tables

There is a separate appendix to module four which looks at statistical significance, and shows how to use NSDstat to investigate this.

Glossary

Also there is a short glossary of statistical terms, which are referred to in the four modules. The electronic versions of the materials (e.g. in word or the web) can link directly to this glossary.

In addition, there are two general guides to finding and investigating data and documentation on the UK Data Archive site:
- Understanding of concepts of operationalisation and validity

- Understanding of content and usage of metadata

- Use of internet to explore metadata

- Understanding of basic descriptive statistics and frequency tables

- Use of computer program to generate descriptive statistics, graphs and univariate tables
- Understanding of concepts of association and independence

- Use of computer program for recoding data

- Use of computer program for construction of 2-way table

- $\quad$ Analysis of 2-way tables 
Module 5. Searching for evidence: sources of crime data

This module shows how to search the UK Data Archive website to find out which studies have been conducted on any given topic

- Get a tour of some of the resources available on the web, including

- UK Data Archive (UKDA)

- Social Science Information Gateway (SOSIG)

- Learn how to search for other data

- Get a list of links to other useful sites

Module 6. Browsing and analysing evidence: a guide to using NESSTAR

This guide shows how to use the on-line interactive Nesstar website to obtain information about studies, such as data collection details, related publications and even the questionnaire itself. The guide also shows how to use the site to establish which variables are in a dataset, and to produce tables and graphs from the data.

- Get an introduction to the online data system Nesstar

- Find out how to access and browse data using Nesstar

- Become familiar with the British Crime Survey dataset

- Learn how to produce tables and graphs online
- $\quad$ Resource discovery on the web

- $\quad$ Finding surveys at the UK Data Archive (UKDA)

- Exploring the Social Science Information Gateway (SOSIG)

- Accessing and browsing data using online resources

- $\quad$ Familiarity with the British Crime Survey dataset

- $\quad$ Producing tables and graphs 


\section{Appendix B: Acronym Check}

$\begin{array}{ll}\text { ALT } & \text { Association for Learning Technology } \\ \text { CHCC } & \text { Collection of Historical and Contemporary Census Data and Related Materials } \\ \text { DfES } & \text { Department for Education and Skills } \\ \text { ESDS } & \text { Economic and Social Data Service } \\ \text { ESRC } & \text { Economic and Social Research Council } \\ \text { FE } & \text { Further Education } \\ \text { GCE } & \text { General Certificate of Education } \\ \text { HE } & \text { Higher Education } \\ \text { JISC } & \text { Joint Information Systems Committee } \\ \text { NNA } & \text { National Numeracy Network } \\ \text { MAA } & \text { Mathematical Association of America } \\ \text { SDiT } & \text { Survey Data in Teaching Project } \\ \text { UKDA } & \text { UK Data Archive } \\ \text { VTS } & \text { Virtual Training Suite } \\ \text { X4L } & \text { Exchange for Learning Programme }\end{array}$

\section{Notes}

${ }^{1}$ Contact: Louise Corti, UK Data Archive, Colchester, Essex CO4 3SQ, UK. Phone: +44 1206 872145. Survey Data in Teaching Project (SDiT) Internet http://x4l.data-archive.ac.uk/.Email: corti@essex.ac.uk

${ }^{2}$ Economic and Social Data Service (ESDS) web site: http://www.esds.ac.uk

${ }^{3}$ UK Data Archive (UKDA) website: www.data-archive.ac.uk

${ }^{4}$ JISC Exchange for Learning Programme (X4L) available at: http://www.jisc.ac.uk/index.cfm?name=programme_x41

${ }^{5}$ Part of this paper was presented at the IASSIST Conference held in Ottaowa in May 2003 in the session on "Advancing Research and Data Literacy: Empowering Users".

${ }^{6}$ Rice, Robin et al. (2001), Report on Use of Data In Teaching and Learning, Edinburgh University. Available at: http:// datalib.ed.ac.uk/projects/datateach.html

${ }^{7}$ Economic and Social Research Council (ESRC) (2001), Postgraduate Training Guidelines. Available at: http://www.esrc. ac.uk/esrccontent/postgradfunding/POSTGRADUATE_TRAINING_GUIDELINES_2001.asp

${ }^{8}$ Smith, A. (2004), 'Making Mathematics Count'. (Smith 2004). Available at: http://www.mathsinquiry.org.uk/

${ }^{9}$ CensusAtSchool (2003), Nottingham Trent University, created by the Royal Statistical Society (RSS) Centre for Statistical Education. Available at: http://www.censusatschool.ntu.ac.uk/

${ }^{10}$ Tomlinson Report (2004), The Final Report of the Working Group on 14-19 Reform, Department for Education and Skills. Available at: http://www.14-19reform.gov.uk/

${ }^{11}$ Steen, Lynn (2004), Quantitative Literacy: Why Numeracy Matters for Schools and Colleges, MAAOnline: http://www. maa.org/Q1/index.html 
${ }^{12}$ Information about the Carleton College quantitative literacy grant entitled "Quantitative Inquiry Reasoning and Knowledge to Strengthen the Educational Foundations of Citizenship" can be found at: http://webapps.acs.carleton.edu/news/

?content $=$ content $\&$ module $=\& i d=72301$

${ }^{13}$ See http://www.statlit.org/

${ }^{14}$ Collection of Historical and Contemporary Census Data and Related Materials (CHCC) (2003), Universities of Manchester, Leeds, Glasgow and Essex, Sept 2003. Available at: www.chcc.ac.uk

15 The ESDS holds a rrange of key UK survey series deposited by the Office of National Statistics and other government departments, including the Labour Force Survey, the General Household Survey, the Health Survey for England and the Expenditure and Food Survey. See http://www.esds.ac.uk/government/surveys/

${ }^{16}$ Home Office. Research, Development and Statistics Directorate and National Centre for Social Research, British Crime Survey, 2000 [computer file]. 2nd Edition. Colchester, Essex: UK Data Archive [distributor], December 2003. SN: 4463.

${ }^{17}$ NESSTAR: the UKDA's online survey data browsing and download system.

UK Data Archive catalogue available at: http://NESSTAR.esds.ac.uk/webview/index.jsp

${ }^{18}$ Social Science Information Gateway (SOSIG) aims to provide a trusted source of selected, high quality Internet information for researchers and practitioners in the social sciences, business and law. It is part of the UK Resource Discovery Network (RDN). Available at: http://www.sosig.ac.uk

${ }^{19}$ The RDN Virtual Training Suite (VTS) is a set of free online tutorials designed to help students, lecturers and researchers improve their Internet information literacy and IT skills. Available at: http://www.vts.rdn.ac.uk/

${ }^{20}$ National Statistics Online (NS) provides information about Britain's economy, population and society at national and local level, through summaries and detailed data releases. Available at: http:/www.statistics.gov.uk/

${ }^{21}$ Higher Education Funding Councils. Joint Information Systems Committee. Exchange for Learning Programme. Survey Data In Teaching Project, British Crime Survey, 2000 : X4L SDiT Teaching Dataset [computer file]. Home Office. Research, Development and Statistics Directorate, National Centre for Social Research, [original data producer(s)]. Colchester, Essex: UK Data Archive [distributor], May 2004. SN: 4918. Available at: http://www.data-archive.ac.uk/findingData/snDescription. asp? $\mathrm{sn}=4918 \& \mathrm{key}=\mathrm{bcs} \& \mathrm{catg}=\mathrm{xmlAll}$

22 NSDStat is a demonstration version of very simple and user-friendly data analysis software, which is utilised in the last two of the teaching modules were created. This is a very easy Windows-based program that enables students to examine the British Crime Survey data for themselves, and produce their own tables and graphs. This program was developed for use in schools and colleges by the Norwegian Social Science Data Archive (NSD), and is the analytical engine behind the NESSTAR website. A program automatically installs the SDiT teaching version of the data.

${ }^{23}$ The key skills document maps the six modules to the six UK QCA Key Skills Levels 3 and 4 requirements for $16-19$ years olds in education. The mapping of modules and resources to syllabi and Key Skills (levels 3 and 4) requirements for 16-18 year olds undertaken in the project was attractive to FE tutors (see Tutor Guide for mapping), suggesting that all elearning resources should be mapped to the syllabus as precisely as possible. The investigation of crime from a sociological perspective, and the application of statistics and data handling covered in the resources address: Application of Number, Information Technology and Problem Solving, while the group exercises cover Communication. The web resources, which can be used as self-paced exercises, may further contribute to Improving own Learning and Performance. The mapping can be found at: http://x4l.data-archive.ac.uk/learning/keyskills.asp. See also http://www.qca.org.uk/14-19 for further information about the development of the national Key Skills.

${ }^{24}$ Dr. Jon Mulberg was the main project officer for the last 12 months of the project. He is the author of Figuring Figures: An Introduction to Data Analysis (2001), Harlow: Prentice Hall.

${ }^{25}$ SDiT case studies available at: http://x4l.data-archive.ac.uk/learning/tutorsguide.pdf 
${ }^{26}$ More information about VLEs can be found at: http://www.jisc.ac.uk/index.cfm?name=mle_related_vle. For Content Packaging (e.g. IMS) see: http://www.cetis.ac.uk/members/x41/articles/relevantspecs.

${ }^{27}$ The UKCMF (UK Common Metadata Framework) is a subset of the Learning Object Metadata (LOM) produced by IEEE. See http://www.cetis.ac.uk/members/x4l/faq/Metadata/20030213162013. The JORUM Online Repository for Learning and Teaching Materials is available at: http://www.jorum.ac.uk.

${ }^{28}$ The Association for Learning Technology (ALT) is a professional and scholarly association which seeks to bring together all those with an interest in the use of learning technology. It has over 200 organizations and over 500 individuals in membership. Available at: http://www.alt.ac.uk/

${ }^{29}$ ESDS programme of events available at: http://www.esds.ac.uk/news/esdsforthevents.asp 